\title{
Introducing the "15-Minute City": Sustainability, Resilience and Place Identity in Future Post-Pandemic Cities
}

\author{
Carlos Moreno, Zaheer Allam *, Didier Chabaud, Catherine Gall and Florent Pratlong
}

\begin{abstract}
Chaire Entrepreneuriat Territoire Innovation (ETI), Groupe de Recherche en Gestion des Organisations (GREGOR), IAE Paris-Sorbonne Business School, Université Paris 1 Panthéon-Sorbonne, 75013 Paris, France; carlos.moreno@univ-paris1.fr (C.M.); chabaud.iae@univ-paris1.fr (D.C.); Catherine.Gall@chaire-eti.org (C.G.); Florent.Pratlong@univ-paris1.fr (F.P.)

* Correspondence: zaheer.allam@chaire-eti.org
\end{abstract}

Citation: Moreno, C.; Allam, Z.; Chabaud, D.; Gall, C.; Pratlong, F. Introducing the "15-Minute City": Sustainability, Resilience and Place Identity in Future Post-Pandemic Cities. Smart Cities 2021, 4, 93-111. https://doi.org/10.3390/smartcities 4010006

Received: 3 December 2020

Accepted: 6 January 2021

Published: 8 January 2021

Publisher's Note: MDPI stays neutral with regard to jurisdictional clai$\mathrm{ms}$ in published maps and institutional affiliations.

Copyright: $\odot 2021$ by the authors. Licensee MDPI, Basel, Switzerland. This article is an open access article distributed under the terms and conditions of the Creative Commons Attribution (CC BY) license (https:// creativecommons.org/licenses/by/ $4.0 /)$.

\begin{abstract}
The socio-economic impacts on cities during the COVID-19 pandemic have been brutal, leading to increasing inequalities and record numbers of unemployment around the world. While cities endure lockdowns in order to ensure decent levels of health, the challenges linked to the unfolding of the pandemic have led to the need for a radical re-think of the city, leading to the re-emergence of a concept, initially proposed in 2016 by Carlos Moreno: the "15-Minute City". The concept, offering a novel perspective of "chrono-urbanism", adds to existing thematic of Smart Cities and the rhetoric of building more humane urban fabrics, outlined by Christopher Alexander, and that of building safer, more resilient, sustainable and inclusive cities, as depicted in the Sustainable Development Goal 11 of the United Nations. With the concept gaining ground in popular media and its subsequent adoption at policy level in a number of cities of varying scale and geographies, the present paper sets forth to introduce the concept, its origins, intent and future directions.
\end{abstract}

Keywords: 15-minute city; urbanism; sustainability; collective intelligence; proximity; smart cities; Carlos Moreno; walkability; humane cities

\section{Introduction}

While the advent of cars was celebrated for the numerous possibilities it brought in terms of mobility, trade and social class association, it has had numerous documented negative and severe impacts on the socio-economic fabric. In cities, cars changed the dynamics of urban planning, opening doors for linear and perpendicular city grids and the devastating consequences of urban sprawl [1]. The wide-ranging availability of cars flooding streets in cities, as noted by Gössling [2], has led to continuous negative impacts on both biodiversity and quality of life, linked to negative outcomes such as increased traffic congestions, which, besides psychological and social tolls, translate to time and economic loss. Such outcomes are also linked to low air quality as a result of increased emissions and the energy demand (fuel) to keep vehicles on the roads. Appleyard [3] interestingly notes that the availability of cars has also resulted in increasing financial burdens on different households, resulting from the lost time in traffic, the demand for fuel and the increasing cost of vehicle maintenance. Regarding biodiversity, cars have led to urban sprawl, negatively impacting green reserves and forest and arable lands as more people opt to reside in those areas to escape chaotic urban environments [4]; entering a catch-22 situation where the need for habitable environments need to be balanced with new infrastructures tied to accessibility to basic amenities, which are not always observed in sprawled areas.

This form of urban approach could be traced back to the celebrated modernist architect le Corbusier, who laid the blueprint for urban sprawl in his bid to escape the unsustainable urban environment. He supported that cities were not efficiently planned for them to be considered "sustainable", and the only alternative was to demolish and re-plan and 
rebuild with sustainable dimensions being infused. However, his immediate proposed solution promoted urban sprawl and has, over time, proven distasteful—and coined by Jane Jacobs [5] as being "the most dramatic idea" —as it encouraged excessive reliance on automobiles. The creation of urban environments accommodating cars has prompted the demand for vehicular-dependent cities, and this has, over time, been satisfied through the mass production of automobiles, which paradoxically aligned with the global agenda of industrialization and oil dependency, which have been later understood as being among the epoch where emissions escalated the impacts of climate change.

Today, our car-dependent urban planning legacy outlines deep-rooted inequalities, especially in the social and economic spheres, and has become the center for unsustainable practices [6]. However, in some major cities, there are some efforts to revamp and encourage public transit mechanisms such as the use of public transport with the objective of reducing private car ownership and emissions [6,7].

One unlikely "boost" towards achieving sustainability in cities came through the emergence of the COVID-19 pandemic, which-due to numerous challenges-prompted the need for novel and innovative mechanisms for cities to pursue their economic activities while enforcing strict health protocols [8]. However, before innovations such as the use of virtual communication options, cities that were partially or totally locked down experienced unprecedented challenges such as the shortage of basic supplies such as food. A sizeable number of urban residents also faced unemployment as companies and institutions downscaled due to the low demand and supply of basic materials and services [9]. The emergence of this pandemic exposed the vulnerability of cities in their current establishment and the need for a radical re-thinking, where innovative measures need to be tailored to ensure that urban residents are able to cope and continue with their basic activities, including cultural ones, to ensure that cities remain both resilient and livable in the short and long terms.

The need for this radical re-think, coupled with pressing socio-economic issues, led cities to adopt urban planning mechanisms to ensure that quality of life is preserved beyond the fractures that the virus will possibly leave as legacy in cities. On this note, policy makers view it as a necessity to provide proximity-based services to inhabitants by reviewing urban policies, particularly transportation, viewed as a connective thread to solving other issues. In view of this background, we propose to study a conceptual approach that has captured the attention of many politicians around the world: the "15-Minute City", as imagined by the first author, Carlos Moreno, the implementation of which was accelerated during the COVID-19 pandemic.

With this backdrop, we map recent urban trends pointing to the "15-Minute City" concept and analyze similar approaches that insist on the concept of "chrono-urbanism" as a way to improve quality of life in cities-the 15-minute walkable neighborhood proposed by Weng et al. [9] and the 20-Minute City model, advanced by Da Silva et al. [10]—as viable models for modern cities to address their underlying urban challenges. Through this approach, we explore the "15-Minute City" concept, introduced by Carlos Moreno, and discuss its merits and areas for future research.

This perspective paper introduces the 15-Minute City model as an alternative planning approach in light of the global COVID-19 pandemic. This perspective is compared with other emerging, yet similar, planning models, where the differences are mapped and explained in Section 4, while the fifth section comprehensively introduces and explains the proposed concept, including four distinctive dimensions pertinent to the proposed planning model. That section is then succeeded by the discussion and conclusion section.

\section{A Perspective on the 15-Minute City as an Urban Planning Pandemic Response}

Since it was first reported, the impacts of the COVID-19 pandemic are still unfolding, with numerous countries grappling with a second wave of the virus outbreak, reported as being more lethal than the first one [11,12]. Due to this, most countries were contemplating the re-introduction of the already eased containment measures to mitigate further spread 
of the virus. The re-introduction of stringent health protocols and lockdown measures is expected to further dent the economic and social dimensions of cities, which were trying to rise from the shock of the first brutal wave, especially on urban dwellers [13]. The situation could have been complicated by the modernist urban planning concepts that created fragmented cities and communities, being heavily automobile-dependent. With this legacy, most urban fabrics, though connected, are not easily accessible without a heavy reliance on automobiles. Such a situation had caused bottlenecks in service delivery and calls for the need for more appropriate urban planning mechanisms as a means of pandemic response in different cities. Going further, Allam and Jones [8] called for the need for post-pandemic urban planning mechanisms to dwell into urban resilience for higher livability dimensions. This is followed by Carlos Moreno through his book 'Droit de cité: De la "ville-monde" à la "ville du quart d'heure"' [14].

One such temporary urban response that has proven efficient in lockdown cities, where vehicular use had drastically declined, was the inclusion of bicycle lanes to counter the impacts arising from vehicular movement restrictions. De Vos [15] notes that encouraging bicycle use during this pandemic has had numerous benefits including on the health and well-being but also in helping people maintain social contact while observing health protocols and adhering to the long-term goals of sustainability. The influence of bicycles on promoting sustainable mobility and COVID-19 abatement is evident in cities such as Berlin in Germany, where already, when the pandemic broke, two temporary bike lanes were set up [16], followed by the pursuance of long-term policies on the subject [17]. Another example is in New York City, which witnessed an upsurge in bicycle usage by over $67 \%$ in March, where its success led to calls for permanent transformation to become a "bicycle city" [18]. In Beijing, bicycle usage also increased by over $150 \%$ as people tried to avoid public transport and comply with the restrictions on private car usage [19]. In Copenhagen, bicycle shops were considered essential service providers and were never closed, even when other non-essential service providers were forced to [20]. Adding to this, other services linked to public spaces, parks and cultural services and amenities—often overlooked in the past-saw their popularity and demand rising during the pandemic. This new-found demand for soft mobility and community-based urban services is forcing mayors and city managers to facilitate and, where possible, render those temporary urban responses permanent, even after the COVID-19 pandemic. A mapping of temporary urban services that emerged in cities during the COVID-19 pandemic is outlined below.

As is depicted in Table 1 below, the world has been amassed with innovative temporary urban infrastructures, which has helped to partially deal with some challenges presented by the pandemic. Such success highlights that the public wishes that urban managers will concentrate henceforth on investing in proximity-based needs rather than rolling out further investments in large infrastructural projects as a means of economic support through COVID-19 relief packages. For instance, in the Netherlands, micro-marketscreated by Timmermans-helped to ease congestion in supermarkets, proving essential in ensuring that locals were able to access basic commodities within their close proximity, hence reducing the risk of infection in so doing [21]. Another temporary infrastructure is a maze-like park, introduced in Austria to help locals experience green spaces as they maintain social distancing measures [22]. The architectural design of the parks made them implementable in any open space, maximizing, in effect, the use of unused public spaces in cities, especially those challenged with land scarcity for establishing public parks. 
Table 1. Summary of temporary urban services emerging during the COVID-19 pandemic.

\begin{tabular}{|c|c|c|c|c|}
\hline Region & City & $\begin{array}{c}\text { Temporary } \\
\text { Infrastructure Change }\end{array}$ & $\begin{array}{c}\text { Date Im- } \\
\text { plemented }\end{array}$ & Ref. \\
\hline \multirow[t]{5}{*}{ EU } & Berlin & Bicycle lane & March 2020 & $\begin{array}{c}\text { District Office } \\
\text { Berlin [16] }\end{array}$ \\
\hline & Vienna, Austria & Maze-like parks & April 2020 & Zhekova [22] \\
\hline & $\begin{array}{l}\text { Rotterdam, the } \\
\text { Netherlands }\end{array}$ & $\begin{array}{c}\text { Hyperlocal } \\
\text { micro-markets }\end{array}$ & April 2020 & Davies [21] \\
\hline & Turin & $\begin{array}{l}\text { Shipping container } \\
\text { hospital }\end{array}$ & April 2020 & Stevens [23] \\
\hline & Edinburgh & $\begin{array}{c}\text { Bicycle and walking } \\
\text { zones }\end{array}$ & $\begin{array}{c}\text { August } \\
2020\end{array}$ & Waller [24] \\
\hline \multirow{8}{*}{$\begin{array}{l}\text { North } \\
\text { America }\end{array}$} & Oakland & Bicycle lane & April 2020 & Coulon [25] \\
\hline & Philadelphia & Bicycle lane & March 2020 & Morris [19] \\
\hline & Denver & Bicycle lane & April 2020 & Swanson [26] \\
\hline & Minneapolis & Bicycle lane & April 2020 & $\begin{array}{l}\text { Minneapolis Park and } \\
\text { Recreation Board [27] }\end{array}$ \\
\hline & Minneapolis & Bicycle lane & April 2020 & $\begin{array}{l}\text { Minneapolis Park and } \\
\text { Recreation Board [27] }\end{array}$ \\
\hline & Dallas & Pop-up stores & April 2020 & Redman [28] \\
\hline & Dallas & Outdoor restaurant & April 2020 & Brandon [29] \\
\hline & Seattle & $\begin{array}{c}\text { Tiny houses for } \\
\text { homeless }\end{array}$ & April 2020 & Lee [30] \\
\hline $\begin{array}{c}\text { South } \\
\text { America }\end{array}$ & Bogotá & Bicycle lane & March 2020 & Schwedhelm, et al. [31] \\
\hline \multirow{2}{*}{ Oceania } & Vancouver & Bicycle lane & March 2020 & City of Vancouver [32] \\
\hline & Calgary & Bicycle lane & March 2020 & Smith [33] \\
\hline
\end{tabular}

Such temporary infrastructures are just an example of the many that could be implemented in the pursuit of the "15-Minute City" concept [34]. The success of this concept, as it has been shown in the city of Paris under the leadership of Mayor Anne Hidalgo, has been hailed as a potent urban planning concept that will lead to an economic boost, while bringing about social cohesion and interaction and help create sustainable ecosystems in cities, more so after the experiences of COVID-19 and associated containment measures. While some of the features of the "15-Minute City" concept had been temporarily adopted in different cities after the impacts of COVID-19, its adoption in long-term planning would result in a higher quality of life as proximity to basic services would help in saving time wasted in traffic, thus promoting sustainable mobility [35]. This will aid in efforts to reduce emissions as envisioned in the Paris agreement and promote higher cultural outputs, amongst others. For instance, by re-thinking the transportation system to create more biking and walkable streets, the challenges of private car ownership will be somehow addressed as they will be reduced as more people embrace biking culture. In addition, as expressed by Reimer [36], the adoption of the "15-Minute City" concept will also open gateways for more novel digital innovations such as bike-sharing technologies that would increase the high livability experiences of urban residents. For instance, as is expressed by Gehl [37], the re-thinking of cities to facilitate walkability and cycling would, in turn, inspire the creation of parks, squares and public places within neighborhoods, and by doing so, it would help to bridge the social inequality in accessing such facilities, which are not always available for everyone in a car-dependent city.

\section{An Early Mapping of the 15-Minute City Concept and Emerging Variations}

Since the concept's proposal in 2016 and its wide coverage in the popular media, followed by its adoption at policy level in Paris, leading to discussions in other global cities, there have been emerging variations of the concept that seem to portray the same 
principle philosophy of "chrono-urbanism" while supporting the need for proximity-based indicators to better service urban areas. These approaches of chrono-urbanism are in line with studies underlining the importance of urban rhythms in order to understand the quality of life in cities: especially space is relevant only as it is coupled with temporal dimension [38,39]. The first two notable variations to the concept are introduced in Sections 3.1 and 3.2 below.

\subsection{The 15-Minute Walkable Neighbourhoods}

Weng, et al. [40] explore the significance of 15-min walkable neigborhoods that cater for the need of all the demographics. In particular, the authors promote this as a way of promoting the health dimensions of the residents especially in voiding non-communicable diseases like obesity. However, the authors were concerned that the 15-minute walkable neigborhoods could present some form of social inequality in relation to attributes such as age and economic status. That is, they opined that the basic amenities that younger people like children may be interested in (such as sport facilities and playgrounds) may be different from those elderly people may be interested in and noting that such different groups have different walking behaviors and speed, urban planners need to be informed. However, the authors observed that within walkable distance, the social needs of different demographic groups were not sufficiently provided, and at any given time, one or more group was left disadvantaged in provision of basic amenities.

As advanced in the "15-Minute City" concept, the authors are of the opinion that basic urban amenities need to be provided in close proximity to urban centres, and such should not disadvantage people in respect of their socioeconomic status or age. This article is also inspired by the perceived need to maintain close social ties for increased liveability indexes. On this, it is noted that in most cities, including Shanghai which is the case study for the article, basic amenities are located in the central areas while the peripheries where residential areas are located have those amenities sparsely distributed; thus, making walkability almost impossible. Philosophically, the authors view the planning of Shanghai city with the same lens as Le Corbusier, who preferred a city that seem to be strongly ordered, but which ultimately necessitated the need for automobiles to access all the available amenities.

While this article principally correlates with the concept by Moreno, it differs on how it emphasizes the need for walkable neigborhoods as a way of promoting a healthy lifestyle. Furthermore, the need for a 15-Minute City is equally focused on other dimensions, relating to ecological sustainability, promoting social interactions and citizen's participation and addressing automobile dependence by emphasizing on proximity of all basic services.

\subsection{The 20-Minute City}

Another variation to the "15-minute city" concept is by Capasso Da Silva, et al. [41] who note that it is possible to plan cities that are accessible within a 20-Minute walk, cycling or transit. The authors' conviction is that during the planning stages, concentration should be on accessibility rather than transportation aspects which have inspired most cities to date. In the article, the city of Tempe, Arizona has been forwarded as the case study, and the authors express that though the city is accessible within a 20-minute of cycling or transit, it is experiencing some form of sprawl that would eventually dilute this concept of "20-Minute City". That is, with the current trends of urban sprawl, the concept would only hold if residents depended on cars to access basic essentials.

Though the article advocates for a "20-Minute City", it aligns with Carlos Moreno's concept of "15-Minute City", especially on how it emphasizes on accessibility and the need to reduce mobility. The authors are emphatic on the need for cities to consider their built environment to allow for accessibility in the city. According to them, planning emphasis need to focus on ensuring streets in urban areas are organised in such a way that they promote accessibility to different parts of the city within 20 Minute walking radii, and such planning would sometimes require restricting or reorientation existing infrastructures 
Apart from accessibility, this article differs with the concept of Moreno in that it does not emphasize on need for sustainable social interactions and participation of urban residents. There also seems to be a lack of emphasize on the need for proximity of basic amenities and services, and instead, its concentration is on accessibility to opportunities, which in this case are aligned to job opportunities; an interesting dimension that strongly relates to automobile usage. While the emphasize on access to opportunities is novel, such does not expressly highlight how such accessibility would help in minimising reliance on automobiles by residents in their search for services like parks, playgrounds, schools, shopping centres and others. Another philosophical divergence that these authors have with the "15-Minute City" concept by Moreno is that they seem to advocate for a different distance based indicator. This means that, though the basic amenities would still be available, in the 20-minute city, they would be a bit further placed than in the concept advocated by Moreno. It would also mean that much land and more resources will be required to actualise this planning model. However, beside those divergences, the ultimate objective in the two concepts are similar, with proximity, and reduction of car reliance being some of those objectives.

\section{On Smart Cities, Collective Intelligence and Place Identity}

The"15-Minute City" concept, further expounded on in Section 5 below, aligns with the tenet of "chrono-urbanism" and advocates for increased proximity, social interaction captured by the "density" dimension, digitalisation and diversity pillars which in essence would lead to more closely knitted community fabrics. This would by a larger margin be facilitated by the increased technological advancements that have led to the emergence of such novel urban planning models like the Smart City concept, which is based on the success of digital revolution [42]. On this, the underlying principle of Smart City concept is the deployment of diverse technologies to optimize different urban fabrics. Numerous authors [43-47] champion this concept as a novel model that can assist cities to achieve sustainability and improved liveability status for an increased quality of life for their residents.

The achievement of Smart City concept in the current epoch is tied to availability of a rich interconnected array of Internet of Things (IoT) devices that have the capacity to collect, and send data to a centralized network, where this data is then computed, analyzed and distributed, in real-time to respective urban department for actions [48]. The availability of IoT devices, which Alam [49] note will be in excess of over 75 billion devices by 2025, coupled with technologies such as Artificial intelligence (AI), Big Data, Machine Learning and Crowd Computing and others is expected to actualize the proposed 15-Minute City concept. At the core of the concept is the availability of different amenities and urban services; which with technology, would render it easier to use available data on different aspect to ensure novel urban planning to ensure optimal service delivery within intended areas of proximity.

Aligning with calls of technological integration in cities to achieve the dimensions outlined in the Sustainable Development Goal (SDG) 11, pertaining to safety, sustainability, resilience and inclusivity, the use of diverse technologies, smart devices and sensors can lead to this actualisation and in effect render a higher quality of life. It is further observed that improving the quality of life of urban residents leads to a focus on four major converging aspects: (1) promoting social inclusion for better social cohesion and combating exclusion, (2) reinventing urban infrastructure to adapt to 21st century lifestyle changes, (3) building on the digital revolution, (4) taking into account major urban environmental issues, including the challenges of climate change. In this regard, different aspects of the urban fabric are interlinked using an array of IoT devices, generating a rich database, critical in providing invaluable insights shaping policies and projects. As noted by Ferrero Bermejo, et al. [50], with the data, cities pursuing "smartness" are able to address challenges like increasing energy demand, traffic issues, social inequality in housing and in provision of services like health, improve economic status of residents and confront the 
challenge of sustainability heads-on. In reference to the 15-Minute City concept, technology use is thus novel, especially in ensuring that alternative solutions -aligning more with the tenets of the SDG 11, are available in diverse areas, including that of the transport sector in order to repair cities from the decades of fracture that car-driven policies left as legacy. For instance, with technology such as AI, IoT and Big Data, technologies such as bike sharing [51], online shopping [52], car sharing [53], and drone delivery services (currently being tested by Amazon [54]), amongst others, are on the rise in different cities. Such services are geared to ensure that people are safe and on time by eliminating the need to travel to purchase different items, and where they have to travel, the use of bicycles, or walking ensures they experience no traffic and are able to safe on costs that would have gone to autos. However, technology here, should not only be about removing the need to access and engage in the primary activities necessary to sustain an urban life, but also aid -through the use of policies, to ensure that a high quality of life is achieved while doing so.

In respect to the ecological aspects promoted in the "15-Minute City" concept, modern technologies have been identified as being a proponent in the prospects of achieving sustainability and resilience in cities. For instance, one area that Smart City researchers advocate for is the adoption of mixed-use housing models that promote compactness [21,55], efficient use of resources like energy and water [56], increase in proximity [57] and in the promotion of adequate land use $[57,58]$. When compounded, all these factors have a positive bearing in promoting ecological sustainability, while at the same time enhancing the quality of life of the citizens. Further, by adopting modern technology, especially in the building, planning and construction sectors, modern trends being pursued in the concept encourage the incorporating of green and civic aspects in building and planning. That is, encouraging the use of green building and planning systems and technologies, including green spaces in the built environment, embracing use of green roofing and walls among others -through the careful planning, optimisation and retrofitting of spaces and built structures.

Adding to this philosophy, we advocate for the need for quality human interaction and that participatory processes are encouraged at varying scales of planning processes, through conception to after construction, through feedback loops. With modern smart technologies that cities are pursuing, this aspect of interaction is becoming possible, and should become a norm as is widely expressed by Gehl [37]. For instance, in respect to participation in a diverse society, it has been observed that urban managers and planners are now able to interact with residents using different communication platforms through both closed (through intranet systems) and open loop system, like social media. The latter have gained popularity during the last decades since the advent of social media platforms, coupled with the decreasing price of internet connectivity and increasing bandwidth rate (from $2 \mathrm{Mbps}$ in 2000 to over 1 Gbps in 2015 [59]). For the internet, the NCTA [60] notes that the speed increased by over $10,000 \%$ fold in the last 15 years, and is expected to increase even further in the future with the emergence of 6G mobile connectivity technology $[60,61]$ and have become critical tool in generating massive amounts of data, which when processed and analyzed have enabled cities to improve on areas like branding through place identity [62,63]. For instance, there are now cities like Amsterdam, New York and others relying on the power of social media to market, create and advocate for their place identity [64]. Other cities, like Amsterdam, have been using the power digital solution to enhance its position as the ultimate world cycling city [63].

The advantage of this practice is that cities are able to draw not only tourism traffic, but also local ones, which ultimately help improve their economic status through increased job opportunity and increased revenue flow, while capitalizing on resiliency outcomes [65]. The place identity concept also allows cities to create new or capitalize on their inherent and unique heritage like culture, art, education, health and others; thus, allowing them to remain competitive, while retaining their uniqueness and community heritage -which is often an issue in rapidly gentrified cities. Further to this, Parente [66] notes that when place identity is well crafted, deployed and achieved, cities are able to attract new business 
opportunities, and in the long-turn manage to contribute toward improving the quality of lives of its residents, while reverberating positively on adjacent urban areas. The "15Minute City" concept, on its right supports such drives and advocates for the promotion of place identity through the concept of chrono-urbanism, allow those seeking alternative lifestyles -away from the automobile dependent cities, to access almost urban services and amenities within walkable and biking distance.

Regarding the pursuance of social welfare, one area that is key is ensuring that residents are able to enjoy health lifestyles. Such are enhanced through the ability to walk or cycle to different parts of the city within the prescribed $15 \mathrm{~min}$. Besides walking, we support that the substantial amount of time saved for not being in traffic could be directed towards engaging in other health -both physical and mental, enhancing activities. On this front, modern technologies have become accessible and practical, especially due to availability of wearables (including those gathering biodata) and urban sensors and data collection techniques that not only allow people to keep tab of their health, but also provide large datasets that could be used to improve the liveability of the area. Finally, the land use approach of this concept gains from the use of technologies as it can optimally ensure that cities have sufficient land reserves for playgrounds, recreation areas and foot walk and bicycle lanes to achieve the desired dimensions [67] and for maintaining an optimal density that would be supported by available resources.. On this front, the use of Blockchain, smart contracts and fiscal instruments can be tallied to urban development rights and transaction costs to ensure both efficiency and performance while catering for long term policy agendas [68].

\section{Introducing the 15-Minute City Concept}

The 15-Minute City rides on the concept of "chrono-urbanism", which outlines that the quality of urban life is inversely proportional to the amount of time invested in transportation, more so through the use of automobiles. This concept originated from the first author, Carlos Moreno, who advocates for an urban set-up where locals are able to access all of their basic essentials at distances that would not take them more than 15 min by foot or by bicycle. Interestingly, the concept is observed to emanate from his tenets developed in his version of a "living city", outlining how it is necessary to "repair" urban and social fragments, largely fueled by modernist approaches. For the present "15-minute" concept, Moreno supports that residents will be able to enjoy a higher quality of life where they will be able to effectively fulfil six essential urban social functions to sustain a decent urban life. Those include (a) living, (b) working, (c) commerce, (d) healthcare, (e) education and (f) entertainment.

To attain those functions, the urban built landscape needs to be restructured to ensure that it complies with components such as proximity, diversity, density and ubiquity which Moreno opines to be major in the pursuit of cities offering an urban life that could be categorized as being of high value. A case in point where this concept has been tried and tested is in Paris, where Anne Hidalgo, through the program "Paris en Commun", turned towards the "15-Minute City" concept (in French: "La Ville du $\frac{1}{4} \mathrm{~d}^{\prime}$ Heure"), imagined by Carlos Moreno in 2016 [10], in a bid to win a second mandate as Mayor, which she successfully did in June 2020 [69]. This is quite a remarkable achievement, noting that citizens of a pandemic-stricken global city opted for a program highlighting dimensions of resilience and livability over pure economic growth. Following its success there, this concept has now been seen to be replicated in different cities across the globe and aroused the interest of international organizations, which, amongst others, included the C40 Cities [70], the World Health Organisation (WHO) [71], UN-Habitat [72] and the Organisation for Economic Co-operation and Development (OECD) [73] in order to improve the quality of life in the context of COVID-19 and beyond.

While striving to satisfy those components, the six essential social functions are bound to be achieved, with the urban social fabric becoming even more closely knitted and with residents made to interact and participate more in activities that ultimately strengthen their 
social bonds, building character and trust, which ultimately leads to the building of more healthy urban landscapes.

In the current era where the world is experiencing the fourth industrial revolution characterized by ubiquitous deployment of Information Communication Technology (ICT), the 15-Minute City concept is seen as being timely. This is true since ICT is now seen to offer an array of solutions to numerous urban challenges, especially through the Smart City concept [48]. With these technologies, it has been shown that cities could enhance and improve on service delivery as well as promote increasing sustainable practices. The prompt delivery of services is also at the core of the 15-Minute City concept with the ultimate objective of ensuring that the maximum time is available for urban dwellers to accomplish the aforementioned basic social functions. In particular, the time saved from mobility is argued to be critical as urban dwellers do not only waste time on the roads, but they also incur high costs during commuting as well as degrade their life. To put this into perspective, in America, it is estimated that on average, traffic delays leads to a consumption of USD 1010 per year per person, which cumulatively translates to over USD 166 billion per year nationally. On the same note, an average national tally of $54 \mathrm{~h}$ a year are wasted by every average U.S. driver on the road due to traffic [74]. Saving on commuting time also saves the urban environment through the reduced emissions from both vehicles and power plants when fuels are extracted and processed. In addition to reducing time, the transformation that is to take place to ensure that all basic amenities are accessible within reach must ensure that the available urban space is optimized, hence promoting novel land use, which is also critical in reconciling human livability pursuits aligning with the urban ecology.

In respect to the above backdrop drawn from Moreno's 15-Minute City concept, Figure 1 showcases the proposed "modified 15-Minute City" framework, depicting the four identified dimensions that could be incorporated with the already existing one proposed by Moreno. These are (a) Density, (b) Proximity, (c) Diversity and (d) Digitalization. The four dimensions were identified after observing the challenges that different cities across the globe endured during the height of widespread cases of COVID-19 and the subsequent health measures and protocols that ensued aimed at mitigating the spread. As noted above, urban residents endured uncountable challenges, especially in accessing basic essentials which, in most cities, have been sparsely distributed [75-78], whereas if those cities had prioritized the four dimensions identified here within a comprehensive and flexible framework, we believe that numerous issues could have been avoided. For instance, a neighborhood planned such that all basic facilities could be within reach in 15 min or less and that has public spaces ri allow people to maintain decent health standards and practices such as exercising through walking while reducing social contact would be relevant in the time of the present pandemic. Notwithstanding this, going forward, as urban areas embrace the "new normal", the proposed planning model that emphasizes the four components offers a realistic alternative. A description of each of the four dimensions and how they would apply in the proposed planning approach is outlined in the following sub-sections. 


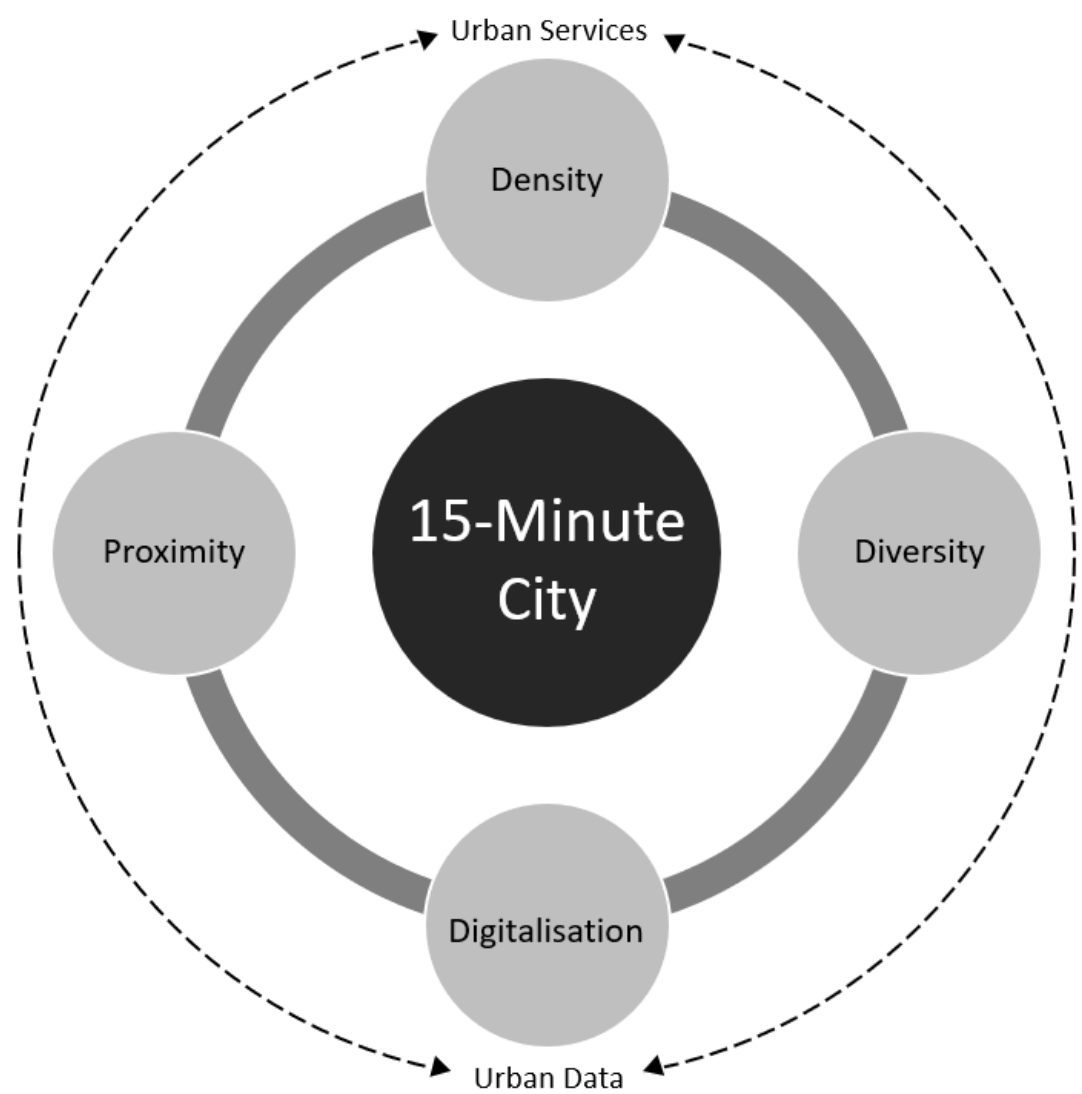

Figure 1. The 15-Minute City framework. Illustration by Authors.

\subsection{Density}

Density is a crucial dimension of the city and its built environment, and this has been noted by numerous researchers $[79,80]$ as having a direct link to travel and diversity. In conventional planning, density is viewed in terms of ultra-high-density buildings, but in the 15-Min City concept, density is viewed in terms of people per kilometer square. That is, in planning for a city that is sustainable, it is supported that it is paramount to consider the optimal number of people that a given area can comfortably sustain in terms of urban service delivery and resource consumption. In earlier planning models, where the emphasis was on creating ultra-high-rise buildings and offices, challenges arose, including the increased overconsumption of resources and over-reliance on fossil fuel energy to power buildings, ultimately leading to an increase in the number of automobiles inspired by centralized planning ideologies. As such, the emphasis here is on the optimal density that ultimately allows sustainability pursuits to be achieved on the economic, social and environmental frontiers.

Salingaros [81] highlights that with an optimal density, it is possible to effectively plan the available space such that all the essentials could be accessible to residents without the need for time- and energy-consuming automobiles. Furthermore, he opined that an optimal density allows for the creation of locally based solutions in areas such as energy generation, food supply and multiple use of available spaces [82,83], where, for example, school playgrounds could be used as parks [84]. In the current urban dispensation, this dimension allows for the creation of public infrastructures such as bicycle lanes and walkable pathways that minimize the requirement for automobiles, hence promoting the achievement of the social functions imagined by Moreno. Our view on this issue aligns with that of Sisson [85], who notes that this dimension also allows for equity in addressing the specific needs of different areas, including communities of varying economic status, while particularly favoring the disadvantaged, especially through the equitable distribution of civic services and in the deployment of services at a reduced cost for cities, rendering 
higher value for both investors and governments. Through this lens, the stand on this perspective paper is that density is a key component favoring the social sustainability dimension of cities [86], and when integrated with the other three dimensions (proximity, diversity and digitalization), the "15-Minute City" model would not only help in improving service delivery and improve livability but also benefit from the advanced technological advancements.

\subsection{Proximity}

This paper promotes the dimension of proximity, which is viewed to be both temporal and spatial. That is, within the 15-min quickly accessible radial nodes, residents in a given neighborhood can readily access basic services. This dimension is critical not only in helping cities reduce the amount of time lost in commuting but also in reducing the environmental and economic impacts of such activity [87]. This also helps in determining social indicators impacting urban residents, especially in a bid to promote social interactions-as advocated for by urban theorists such as Jane Jacobs [5], Christopher Alexander [88,89], Andres Duany [90] and Nikos Salingaros [81,91].

On this, Moreno, advances that this dimension is critical as it allow residents to transition from residential areas, work, commercial areas, education centers, health facilities and other basic institutions in a reduced timespan. Ultimately, this closeness of essential services allows residents to enjoy better service provision both in commercial and public establishments, as the planning model allows for multimodal use of basic infrastructures. For instance, in Paris, where Mayor Hidalgo has embraced this new concept, it is becoming a norm for school playgrounds to be transformed into parks that the public are free to access after school hours [84]. With this and other examples [92], the pursuance of the proximity dimension advanced in this paper is, thus, critical, as it allows local residents to maximize their local public spaces, green spaces and other public infrastructures. It also allows them to maximize the exploitation of their available resources such as heritage for social, economic and environmental benefits. This premise is important as it allows to envision a city through a different perspective, more tailored to the human scale and adaptable to the use of its residents.

In essence, this concept of proximity as advanced in this paper links back to the core the philosophy of chrono-urbanism, emerging from the thematic of "chronotopy", explored by $[38,93,94]$, standing as a coupling of spatial and temporal dimensions. Through this lens, the city can be viewed from a distance-based indicator, leading to a view of time-based urbanism. However, as is demonstrated in this paper, it is not sufficient on its own to actualize this node, as it needs to be connected to the other dimensions to achieve the desired urban transformation.

\subsection{Diversity}

Diversity in the context of the above frame and in the advancement of the 15-Minute City concept is twofold: (i) the need for mixed use neighborhoods which are primary in providing a healthy mix of residential, commercial and entertainment components and (ii) diversity in culture and people.

Having mixed-use neighborhoods is key in sustaining economically vibrant urban fabrics $[95,96]$, ensuring sufficient housing for all the urban residents [70], promoting inclusivity and promoting sustainable practices [97]. In the pursuit of a 15-Minute City model, the adoption of mixed-use neighborhoods is paramount in ensuring that an optimal density and proximity of essential amenities are achieved, while also providing for development of walkable streets and bicycle lanes. This approach ensures that residents can benefit from basic essentials within their residential areas, thus reducing the need for them to travel to access them. This dimension would also aid in ensuring that the sanctity of available public spaces is preserved and upheld and, where possible, that opportunities for creating more public areas are savored, as was advocated for by Whyte [98]. This dimension aligns with that of urban density and proximity, and it is the position of this paper that emphasizing 
its observance in the proposed "15-Minute City" model would help enrich the experience of urban dwellers.

Brookfield [99] expresses that embracing this form of diversity in a neighborhood provides city governments with opportunities to concentrate on improving their service delivery to locals and, in turn, promotes the livability status, maintains property value and enhances community participation and interaction. This is particularly important in promoting a city environment that accommodates different cultures and people, thus promoting social cohesion and helping in creating more social capital [100].

Having a multicultural dimension in a city has positive bearings on the economic front, as locals would also enjoy a wide variety of products such as cultural products and cultural heritage. This would also render an attractive urban landscape for visitors, thus promoting tourism and other related businesses which are essential in creating new business and promoting economic vibrancy, leading to the creation of increased employment opportunities [101].

To maximize those benefits, this dimension requires deployment at varying scales in a city. Not only in an urban scale across a 15-min radius but beyond more minute scales-at building levels.

\subsection{Digitalization}

This dimension is very relevant to the modified 15-Minute City concept, especially in ensuring the actualization of the three other dimensions. In particular, this dimension aligns closely with the Smart City concept from which the 15-Minute City concept can be argued to have, in part, drawn its inspiration. For instance, within the Smart City concept, factors such as inclusivity, resident participation and real-time delivery of services are encouraged through varying platforms—including digital $[53,102,103]$ - just as in the case in Moreno's proposed concept. The achievement of those factors in the Smart City concept is shouldered on the effective deployment of different technologies, and this would have similar far-reaching impacts in the 15-Minute City. For instance, through digital tools and solutions, it would be possible to ensure that biking experiences are enhanced by emphasizing solutions such as bike sharing and the deployment of sensors to ensure the safety and security of cyclists [70,104].

Regarding proximity dimensions, digitalization has been effective, as highlighted through the Smart City concept, where services such as online shopping [52], cashless transactions [105] and virtual communications and interactions [106] amongst others are implemented and promoted. The similar availability of such services within 15-min cities would reduce the need for commuting as some services could be delivered within the comfort of homes or offices. Coupling these with technologies such as smart contracts through Blockchain technology would help to ease security concerns, especially in regard to virtual payments [107]. Digitalization, especially during this period of the COVID-19 pandemic, has made it possible for people to work from home and communicate virtually, and this also been instrumental in reducing social contact and reducing the need to travel from home to offices and other work places. This dimension of proximity-based planning is already emerging from the pandemic and will be expected to stay in the post-pandemic urban jargon.

Additionally, the deployment of digital solutions would greatly help in even exceeding the expectations of the 15-min city, in particular in ensuring that cities are more resilient in areas such as climate change through declining emissions, linked to a reduction in automobile use [108]. This would also be true where the adoption of mixed energy options is embraced $[109,110]$, which help in reduction in over-reliance on non-renewable energy sources. Further, digitalization is crucial in facilitating optimal consumption of resources [48]. Digitalization is also becoming very powerful in job creation through innovations such as iBike that allow people to share bikes in cities, hence encouraging them to avoid the use of personal cars. All those are expected to benefit immensely from the advent of digitalization, which has been seen to be a transversal element, cutting through 
fields, and as such, it is expected that it would also be essential in ensuring the successful deployment of the other three identified dimensions.

\section{Discussions and Conclusions}

In pursuit of transforming urban areas to improve their livability status and resilience, promote sustainability and promote their social and economic aspects, many planning models were proposed over the years and have evolved as a result of their application in varying contexts and geographies. The most recent one is the Smart City concept, which, though it has been progressive in addressing most of the aforementioned issues, has had its shortcomings. From a theoretical perspective, it has the potential to help cities achieve all those objectives, but this potential has been overshadowed by enterprising orientations of ICT technology providers who are inspired solely by the lucrative profit margins that this model presents (valued at USD 410.8 billion in 2020 and is expected to rise to over USD 820.7 billion by 2025 [111]). As a result of this sole pursuit, based on economic agendas instead of solving issues such as non-inclusiveness and social inequalities, the Smart City concept, in some instances, has been found to exacerbate them. For instance, in regard to issues such as cost of living, Pandey [112] notes that urban areas that have transformed and marketed as being "smart" are too expensive for most urban residents to afford. The author explains that this phenomenon is influenced by the emphasis on smart technology rather than the social and economic aspect that such technologies are supposed to address, thus deviating from the dictates of the SDGs, especially SDG 11. On the same page, as noted by Adkins, et al. [113], the concept of the Smart City has acted as a catalyst for the growing inequality in the housing sector, where the real-estate sector is seen to be growing at a rate not proportional to the revenue growth of residents. The growth of the real-estate sector, which is majorly controlled by high-income earners, in turn, has been the fore in advancing the issue of inaccessibility in cities, as it also follows the grid planning systems that have been adopted in many cities. A similar argument is advanced by Gurstein and Hutton [114], where they note that modern urban planning concepts need to be restudied as they have led to unsustainable urban trends, including urban sprawl. The authors further advocate for planning concepts that would reorient urban development into paths that support both environmental and equitable paths, and the present authors believe that the proposed 15-Minute City concept could be among the fitting models.

Those planning weaknesses of most urban planning models, including the Smart City concept, were exposed when the COVID-19 pandemic emerged, necessitating the introduction of stringent health protocols and the re-alignment of economic agendas in view of the increasing socio-economic issues brought about by the pandemic [9]. With the need to observe lockdown measures, social distancing, curfews and other health protocols, it becomes evident that the need for proximity of most basic amenities in most cities has been wanting. Thereby, most urban residents have had to put up with myriads of both economic and social challenges due to inaccessibility of most basic essentials despite availability of advanced soft Smart City technologies. With those challenges, most cities, as currently planned and constituted, need to be re-structured to ensure that in the future, basic services are available at accessible distances, that human interaction would not be disrupted and that cycling and walking would be facilitated to ensure that such healthy protocols would be sustainably observed. Another emerging issue about the Smart Cities model, apparent during the COVID-19 lockdowns, is that most soft technologies support an increasing amount of urban data and their analysis, where this has not, however, directly led to more social interactions, which are now understood as an important planning aspect, especially to help residents weather down both the social and psychological challenges prompted by the COVID-19 pandemic.

In light of this, some aspects advocated for in the "15-Minute City" concept gained traction during the pandemic, despite this model having been proposed as early as 2016 [69]. The selling point of this concept is its emphasis on proximity-based planning, where an urban neighborhood is planned to accommodate an optimal density that would have access 
to basic essential services within a 15-min walking or cycling distance. The proponent of this concept envisions that within that a 15-min radius, residents will manage to experience a higher quality of life as they will be required to travel less to access basic facilities such as public spaces, with increased time and opportunities to interact with other members of the community and accomplish other social functions, which are increasingly important but which have been lacking as a core function of contemporary urban planning models.

The emphasis on accessibility and proximity advanced in the 15-min concept, especially through walking or via cycling, is paramount, since this mode (micro-mobility) has been showcased as having numerous benefits on social, economic and environmental scales. For instance, cities benefit from reduced congestion, reduced pollution (noise, emissions and others) and benefit from beautiful increased green spaces, and well-thought and ordered structures. On the same note, urban residents derive health and economic benefits. They also benefit from increased time and opportunities to exercise and gain social interactions. On the economic front, this model has the potential to unlock numerous potential positive outcomes such as employment, new innovations, creation of urban unique (identity) brands as well as helping to reduce overheads incurred from fuel costs, road maintenance, pollution and other associated costs.

It is noteworthy that while the concept of "chrono-urbanism" may seem arbitrary for some-e.g., why $15 \mathrm{~min}$ and not $17 \mathrm{~min}$ ?-this concept is not rigid in nature and is proposed with the intent to be tailored to individual cities based on both their morphology and specific needs and characteristics. For instance, on this, it is worth noting within 15-min radii, a cyclist would cover a substantial distance compared to residents who may opt to walk. Therefore, the proximity dimension for cyclists would be defined differently from that of those on foot. Indeed, on this matter, there had been other concepts such as 20-min cities [41] and 30-min cities [115], but the bottom line in all of those is the need to underline that proximity-based planning is key in sustaining quality of life and in providing for the basic urban functions. On this subject, the current concept by Moreno is based on the understanding that within the 15-min radius, it is possible for a city to incorporate all the basic essentials, including walking and bicycle lanes, while also incorporating digital solutions to enhance the residents' experience and improve livability status. This thus enables works that support the spatiotemporal dimension of cities to both understand and enhance the quality of life of urban dwellers [35]

As this concept continues to gain acceptability and traction in different global cities, further research is now warranted to showcase how the idea and its elements can be replicated in cities within the global south and those that may be financially constrained to undertake the extensive urban regeneration exercise that this kind of planning model demands. The research gains in importance, noting that some cities can transform and renovate existing infrastructures (without major restructuring) to benefit from bicycle lanes, parks and greener spaces to match the proposed model and to align with the vision of urbanists such as Whyte [98], Alexander [88], Salingaros [81] and Jacobs [5]. This is important as those cities too have experienced similar COVID-19-instigated challenges, leading to economic responses that may leave long-term fragments on both the social and economic fabrics, reverberating on the urban landscape. The pandemic will see long-term changes in cities, prompt the emergence of new socio-economic structures and force new urban planning models that need to adapt to such trends to ensure a safe and sustainable urban future.

Finally, it is observed that the 15-min city is in line with concepts promoting dimensions of proximity, emphasizing walkability and of social interactions within cities. Alexander [30], Gehl [80] and Whyte [112] seem to support this point through their treatises of human-scale urban design. However, even though the concept has gained a rapid adoption by global cities, we support that the operationalization of the 15-min city will require additional studies in order to scrutinize the respective importance and the connections of density, proximity, diversity and digitalization. To do so, it will be necessary to mobilize up-to-date research methods [116] and to discuss its ability to complement 
classical modelization approaches $[79,80]$. One therefore has to consider that beyond its attractiveness for Mayors and institutional organizations such as C40, the 15-min city is opening the way to a research program.

Author Contributions: Conceptualization, formal analysis and validation, C.M.; writing, review and editing, Z.A., D.C., C.G. and F.P. All authors have read and agreed to the published version of the manuscript.

Funding: This research received no external funding.

Conflicts of Interest: The authors declare no conflict of interest.

\section{References}

1. Brown, J.R.; Morris, E.A.; Taylor, B.D. Planning for cars in cities: Planners, engineers, and freeways in the 20th century. J. Am. Plan. Assoc. 2009, 75, 161-177. [CrossRef]

2. Gössling, S. Why cities need to take road space from cars-And how this could be done. J. Urban Des. 2020, 25, 443-448. [CrossRef]

3. Appleyard, D. Livable streets: Protected neighborhoods? Ann. Am. Acad. Political Soc. Sci. 1980, 451, 106-117. [CrossRef]

4. Brown, L.R. Redesigning cities for people: Car-centered urban sprawl. In Eco-Economy: Building an Economy for the Earth; Earthscan: Washington, DC, USA, 2003.

5. Jacobs, J. The Death and Life of Great American Cities; Random House: New York, NY, USA, 1961.

6. Newman, P.; Beatley, T.; Boyer, H. Resilient Cities: Overcoming Fossil Fuel Dependence, 2nd ed.; Island Press: Washington, DC, USA, 2017.

7. Newman, P.; Kenworthy, J. The rise and fall of automobile dependence. In The End of Automobile Dependence; Island Press/Center for Resource Economics: Washington, DC, USA, 2015; pp. 1-31.

8. Allam, Z.; Jones, D.S. Pandemic stricken cities on lockdown. Where are our planning and design professionals [now, then and into the future]? Land Use Policy 2020, 97, 104805. [CrossRef] [PubMed]

9. Allam, Z. Surveying the Covid-19 Pandemic and Its Implications: Urban Health, Data Technology and Political Economy; Elsevier Science: Amsterdam, The Netherlands, 2020.

10. Moreno, C. La Ville du Quart D’heure: Pour un Nouveau Chrono-Urbanisme. Available online: https://www.latribune.fr/ regions / smart-cities / la-tribune-de-carlos-moreno/la-ville-du-quart-d-heure-pour-un-nouveau-chrono-urbanisme-604358 .html (accessed on 3 December 2020).

11. Looi, M.-K. Covid-19: Is a second wave hitting Europe? BMJ 2020, 371, m4113. [CrossRef]

12. Maragakis, L.L. First and Second Waves of Coronavirus. Available online: https://www.hopkinsmedicine.org/health/conditionsand-diseases / coronavirus / first-and-second-waves-of-coronavirus (accessed on 5 June 2020).

13. Wijffelaars, M. Spain's Struggle against Covid-19 Hampers Its Economic Recovery. Available online: https:/ / economics.rabobank. com/publications/2020/october/spains-struggle-against-covid-19-hampers-its-economic-recovery/ (accessed on 5 November 2020).

14. Moreno, C. Droit de Cité; Humensis: Paris, France, 2020.

15. De Vos, J. The effect of Covid-19 and subsequent social distancing on travel behavior. Transp. Res. Interdiscip. Perspect. 2020, 5, 100121. [CrossRef]

16. District Office Berlin. Temporary Installation and Expansion of Bicycle Traffic Facilities during the Pandemic Crisis. Available online: https:/ / www.berlin.de/ba-friedrichshain-kreuzberg/aktuelles/pressemitteilungen/2020/pressemitteilung.911780.php (accessed on 5 November 2020).

17. Connolly, K. 'Cleaner and Greener': Covid-19 Prompts World's Cities to Free Public Space of Cars. Available online: https:/ /www. theguardian.com/world/2020/may/18/cleaner-and-greener-covid-19-prompts-worlds-cities-to-free-public-space-of-cars (accessed on 5 November 2020).

18. Hu, W. A Surge in Biking to Avoid Crowded Trains in N.Y.C. Available online: https://www.nytimes.com/2020/03/14/nyregion/ coronavirus-nyc-bike-commute.html (accessed on 5 November 2020).

19. Morris, D.Z. After Coronavirus, Bicycles Will Have a New Place in City Life. Available online: https://fortune.com/2020/06/15 /bicycles-coronavirus-cities-lime-citi-bike/ (accessed on 5 November 2020).

20. Ibold, S.; Medimorec, N.; Wagner, A.; Peruzzo, J.; Platzer, L. The Covid-19 Outbreak and Implications to Sustainable Urban Mobility-Some Observations. Available online: https://www.transformative-mobility.org/news/the-covid-19-outbreak-andimplications-to-public-transport-some-observations (accessed on 5 November 2020).

21. Davies, S. This is How Coronavirus Could Reshape Our Cities Forever. Available online: https://www.weforum.org/agenda/20 20/05/coronavirus-change-cities-infrastructure/ (accessed on 4 November 2020).

22. Zhekova, D. Is This the Future of Green Public Spaces? Available online: https://www.departures.com/travel/maze-like-parkvienna-social-distancing (accessed on 5 November 2020).

23. Stevens, P. Cura Shipping Container Icus Open in Turin to Combat Covid-19. Available online: https://www.designboom.com/ architecture/cura-shipping-container-icus-turin-covid-19-04-21-2020/ (accessed on 5 November 2020). 
24. Waller, S. \$39M Spent on Temporary Infrastructure in Scotland. Available online: https://www.cyclinguk.org/news / ps39mspent-temporary-infrastructure-scotland (accessed on 10 November 2020).

25. Coulon, J. Oakland is Closing Streets to Most Cars. More Cities Need to Do the Same. Available online: https:/ /www.bicycling. $\mathrm{com} /$ news/a32130879/oakland-temporary-street-closures-coronavirus / (accessed on 5 November 2020).

26. Swanson, C. Denver to Close Several Streets Starting Saturday to Allow for More Outdoor Activities. Available online: https: //www.denverpost.com/2020/04/03/denver-streets-closed-coronavirus-covid/ (accessed on 5 November 2020).

27. Minneapolis Park and Recreation Board. Minneapolis Park and Recreation Board Announces Riverfront Parkway and Road Closures to Help Trail Users Maintain Social Distancing. Available online: https:/ /www.minneapolisparks.org/news/2020/03/ 26/minneapolis-park-and-recreation-board-announces-riverfront-parkway-and-road-closures-to-help-trail-users-maintainsocial-distancing/ (accessed on 5 November 2020).

28. Redman, R. 7-Eleven Pop-Up Store Serves Up Groceries to Dallas Hospital. Available online: https: / / www.supermarketnews. com/retail-financial/7-eleven-pop-store-serves-groceries-dallas-hospital (accessed on 5 November 2020).

29. Brandon, E.M. 7 Smart and Simple Ways Cities Can Encourage Social Distancing in Public Spaces. Available online: https: / / citymonitor.ai/community/smart-and-simple-ways-public-spaces-are-being-adapted-for-social-distancing (accessed on 12 November 2020).

30. Lee, S. The Case for Building Tiny House Villages during the Pandemic. Available online: https://www.realchangenews.org/20 20/06/10/case-building-tiny-house-villages-during-pandemic (accessed on 5 November 2020).

31. Schwedhelm, A.; Li, W.; Harms, L.; Adriazol-Steil, C. Biking Provides a Critical Lifeline during the Coronavirus Crisis. Available online: https:/ / www.wri.org/blog/2020/04/coronavirus-biking-critical-in-cities (accessed on 5 November 2020).

32. City of Vancouver. City Repurposes Eastbound Lanes of Beach Ave for People Walking and Cycling. Available online: https: //vancouver.ca/news-calendar/city-repurposes-eastbound-lanes-of-beach-ave-for-people-walking-and-cycling.aspx (accessed on 5 November 2020).

33. Smith, M. City to Test Road Closures, Putting More Space between Pedestrians. Available online: https://calgaryherald.com/ news/local-news / city-to-test-weekend-road-closures-to-help-calgarians-keep-their-distance/ (accessed on 5 November 2020).

34. Sala, G.; Aboutaleb, A.; Aki-Sawyerr, Y.; Cantrell, L.; Capp, S.; Durkan, J.; Kam-sing, W.; Medina, F.; Plante, V.; Calle, D.Q.; et al. C40 Mayors' Agenda for a Green and Just Recovery; C40 Cities: Rio de Janeiro, Brasil, 2020; pp. 1-43.

35. Sisson, P. How the '15-Minute City' Could Help Post-Pandemic Recovery. Available online: https://www.bloomberg.com/news / articles/2020-07-15/mayors-tout-the-15-minute-city-as-covid-recovery (accessed on 4 November 2020).

36. Reimer, J. The 15-Minute Infrastructure Trend That Could Change Public Transit as We Know It. Available online: https: / /360.here.com/15-minute-cities-infrastructure (accessed on 5 November 2020).

37. Gehl, J. Cities for People; Island Press: Washington, DC, USA, 2013.

38. Mulíček, O.; Osman, R.; Seidenglanz, D. Urban rhythms: A chronotopic approach to urban timespace. Time Soc. 2014, 24, 304-325. [CrossRef]

39. Neuhaus, F. Urban rhythms. In Emergent Spatio-Temporal Dimensions of the City: Habitus and Urban Rhythms; Springer International Publishing: Cham, Switzerland, 2015; pp. 1-11.

40. Weng, M.; Ding, N.; Li, J.; Jin, X.; Xiao, H.; He, Z.; Su, S. The 15-minute walkable neighborhoods: Measurement, social inequalities and implications for building healthy communities in urban china. J. Transp. Health 2019, 13, 259-273. [CrossRef]

41. Capasso Da Silva, D.; King, D.A.; Lemar, S. Accessibility in practice: 20-minute city as a sustainability planning goal. Sustainability 2020, 12, 129. [CrossRef]

42. Cocchia, A. Smart and digital city: A systematic literature review. In Smart City; Springer International Publishing: Cham, Switzerland, 2014; pp. 13-43.

43. Allam, Z.; Jones, D.; Thondoo, M. Cities and Climate Change: Climate Policy, Economic Resilience and Urban Sustainability; Springer International Publishing: Cham, Switzerland, 2020.

44. Allam, Z. Contextualising the smart city for sustainability and inclusivity. New Des. Ideas 2018, 2, $124-127$.

45. Allam, Z. The emergence of anti-privacy and control at the nexus between the concepts of safe city and smart city. Smart Cities 2019, 2, 96-105. [CrossRef]

46. Allam, Z.; Dhunny, Z.A. On big data, artificial intelligence and smart cities. Cities 2019, 89, 80-91. [CrossRef]

47. Allam, Z.; Newman, P. Redefining the smart city: Culture, metabolism and governance. Smart Cities 2018, 1, 4-25. [CrossRef]

48. Allam, Z. Cities and the Digital Revolution: Aligning Technology and Humanity; Springer International Publishing: Cham, Switzerland, 2020.

49. Alam, T. A reliable communication framework and its use in internet of things (IOT). Int. J. Sci. Res. Comput. Sci. Eng. Inf. Techcnol. 2018, 3, 450-456.

50. Ferrero Bermejo, J.; Gómez Fernández, J.F.; Olivencia Polo, F.; Crespo Márquez, A. A review of the use of artificial neural network models for energy and reliability prediction. A study of the solar pv, hydraulic and wind energy sources. Appl. Sci. $2019,9,1844$. [CrossRef]

51. Bouton, S.; Hannon, E.; Knupfer, S.; Ramkumar, S. The Future (s) of Mobility: How Cities Can Benefit. Available online: https: //www.mckinsey.com/business-functions/sustainability/our-insights/the-futures-of-mobility-how-cities-can-benefit (accessed on 15 January 2020). 
52. Reinartz, W.; Wiegand, N.; Imschloss, M. The impact of digital transformation on the retailing value chain. Int. J. Res. Mark. 2019, 36, 350-366. [CrossRef]

53. McKinsey \& Company. Smart City Solutions: What Drives Citizen Adoption around the Globe? Mckinsey Center for Government: Singapore, 2018; pp. 1-60.

54. Herrera, S.; Pasztor, A. Amazon gets U.S. Approval for Drone Fleet, a Package-Delivery Milestone. Available online: https: //www.wsj.com/articles/amazon-gets-u-s-approval-for-drone-fleet-a-package-delivery-milestone-11598913514 (accessed on 12 November 2020).

55. Lehmann, S. Advocacy for the compact, mixed-use and walkable city: Designing smart and climate resilient places. Int. J. Environ. Sustain. 2016, 5, 1-11. [CrossRef]

56. Allam, Z. Enhancing renewable energy adoption in megacities through energy diversification, land fragmentation and fiscal mechanisms. Sustain. Cities Soc. 2019, 101841. [CrossRef]

57. Kourtit, K. Super-proximity and spatial development. J. Reg. Res. 2016, 36, 215-231.

58. Hammad, A.W.; Akbarnezhad, A.; Haddad, A.; Vazquez, E.G. Sustainable zoning, land-use allocation and facility location optimisation in smart cities. Energies 2019, 12, 1318. [CrossRef]

59. Net Information. 1G Vs. 2G Vs. 3G Vs. 4G Vs. 5G. Available online: http://net-informations.com/q/diff/generations.html (accessed on 22 July 2020).

60. NCTA. The Future of Super Fast Internet Is 10G. Available online: https://www.ncta.com/positions/the-future-of-super-fastinternet (accessed on 12 November 2020).

61. Rong, B.; Han, S.; Kadoch, M.; Chen, X.; Jara, A. Integration of $5 g$ networks and internet of things for future smart city. Wirel. Commun. Mob. Comput. 2020, 2020, 2903525. [CrossRef]

62. Allam, Z. Digital urban networks and social media. In Cities and the Digital Revolution: Aligning Technology and Humanity; Allam, Z., Ed.; Springer International Publishing: Cham, Switzerland, 2020; pp. 61-83.

63. Allam, Z. On culture, technology and global cities. In Cities and the Digital Revolution: Aligning Technology and Humanity; Allam, Z., Ed.; Springer International Publishing: Cham, Switzerland, 2020; pp. 107-124.

64. The Place Brand Observer. 31 Innovative Destination Marketing Campaigns and Place Branding Strategies to Serve as Inspiration in 2018. Available online: https:/ / placebrandobserver.com/31-inspiring-destination-marketing-campaigns-place-brandingexamples/ (accessed on 3 July 2019).

65. Richards, G. Cultural tourism: A review of recent research and trends. J. Hosp. Tour. Manag. 2018, 36, 12-21. [CrossRef]

66. Parente, M. Designing the city identity: Strategic and product design for new experiential ways of living, enabling, and interacting with the urban context. BMI 2015, 10, 62-71.

67. Pacheco Rocha, N.; Dias, A.; Santinha, G.; Rodrigues, M.; Queirós, A.; Rodrigues, C. Smart cities and healthcare: A systematic review. Technologies 2019, 7, 58. [CrossRef]

68. Shahab, S.; Allam, Z. Reducing transaction costs of tradable permit schemes using blockchain smart contracts. Growth Chang. 2020, 51, 302-308. [CrossRef]

69. Reid, C. Anne Hidalgo Reelected as Mayor of Paris Vowing to Remove Cars and Boost Bicycling and Walking. Available online: https: / www.forbes.com/sites/carltonreid/2020/06/28/anne-hidalgo-reelected-as-mayor-of-paris-vowing-to-removecars-and-boost-bicycling-and-walking/?sh=ba645d11c852 (accessed on 5 November 2020).

70. C40 Cities Climate Leadership Group. How to Build Back Better with a 15-Minute City. Available online: https: / / www.c40knowledgehub.org/s / article/How-to-build-back-better-with-a-15-minute-city?laguage=en_US\#: \{\}:text=In\% $20 \mathrm{a} \% 20 \backslash \mathrm{T} 1 \backslash$ textquoteright $15 \% 2 \mathrm{Dminute} \% 20$ city $\backslash \mathrm{T} 1 \backslash$ textquoteright $\% 2 \mathrm{C} \% 20 \mathrm{all} \% 20$ citizens $\% 20$ are, and $\% 20$ sustainable $\% 20$ way\%20of\%20life (accessed on 10 November 2020).

71. WHO, World Health Organisation. The World Health Organisation Quality of Life (WHOQOL); World Health Organisation: Geneva, Switzerland, 2012.

72. UN-Habitat. Un-Habitat Key Message on Covid-19 and Public Space; UN-Habitat: Nairobi, Kenya, 2020.

73. OECD. OECD Policy Responses to Coronavirus (Covid-19): Cities Policy Responses; OECD: Paris, France, 2020.

74. Liu, J. Commuters in This City Spend 119 Hours a Year Stuck in Traffic. Available online: https://www.cnbc.com/2019/09/04 / commuters-in-this-city-spend-119-hours-a-year-stuck-in-traffic.html (accessed on 10 November 2020).

75. Allam, Z. Chapter 1-The first 50 days of covid-19: A detailed chronological timeline and extensive review of literature documenting the pandemic. In Surveying the Covid-19 Pandemic and Its Implications; Allam, Z., Ed.; Elsevier: Amsterdam, The Netherlands, 2020; pp. 1-7.

76. Allam, Z. Chapter 2-The second 50 days: A detailed chronological timeline and extensive review of literature documenting the covid-19 pandemic from day 50 to day 100. In Surveying the Covid-19 Pandemic and Its Implications; Allam, Z., Ed.; Elsevier: Amsterdam, The Netherlands, 2020; pp. 9-39.

77. Allam, Z. Chapter 3-The third 50 days: A detailed chronological timeline and extensive review of literature documenting the covid-19 pandemic from day 100 to day 150. In Surveying the Covid-19 Pandemic and Its Implications; Allam, Z., Ed.; Elsevier: Amsterdam, The Netherlands, 2020; pp. 41-69.

78. Allam, Z. Chapter 9-Oil, health equipment, and trade: Revisiting political economy and international relations during the covid-19 pandemic. In Surveying the Covid-19 Pandemic and Its Implications; Allam, Z., Ed.; Elsevier: Amsterdam, The Netherlands, 2020; pp. 119-127. 
79. Ewing, R.; Cervero, R. Travel and the built environment. J. Am. Plan. Assoc. 2010, 76, 265-294. [CrossRef]

80. Cervero, R.; Kockelman, K. Travel demand and the 3ds: Density, diversity, and design. Transp. Res. Part D Transp. Environ. 1997, 2, 199-219. [CrossRef]

81. Salingaros, N.A. Compact city replaces sprawl. In Crossover: Architecture, Urbanism, Technology; 010 Publishers: Rotterdam, The Netherlands, 2006; pp. 100-115.

82. Cervero, R. Efficient urbanisation: Economic performance and the shape of the metropolis. Urban Stud. 2001, 38, 1651-1671. [CrossRef]

83. Lehmann, S. Sustainable urbanism: Towards a framework for quality and optimal density? Future Cities Environ. 2016, 2, 8. [CrossRef]

84. Reid, C. Anne Hidalgo to Make Good on Pledge to Remove Half of City's Car Parking Spaces. Available online: https:/ / www.forbes.com/sites/carltonreid/2020/10/20/paris-mayor-anne-hidalgo-to-make-good-on-pledge-to-removehalf-of-citys-car-parking-spaces / ?sh=423352b916ec (accessed on 10 November 2020).

85. Sisson, P. What is a 15-Minute City? Available online: https://citymonitor.ai/environment/what-is-a-15-minute-city (accessed on 10 November 2020).

86. Dempsey, N.; Brown, C.; Bramley, G. The key to sustainable urban development in UK cities? The influence of density on social sustainability. Prog. Plan. 2012, 77, 89-141. [CrossRef]

87. Marquet, O.; Miralles-Guasch, C. The walkable city and the importance of the proximity environments for Barcelona's everyday mobility. Cities 2015, 42, 258-266. [CrossRef]

88. Alexander, C. The Nature of Order: The Process of Creating Life; The Centre for Environmental Structure: Berkeley, CA, USA, 2002.

89. Alexander, C.; Ishikawa, S.; Silverstein, M. A Pattern Language; Oxford University Press: New York, NY, USA, 1977.

90. Duany, A.; Plater-Zyberk, E.; Speck, J. Suburban Nation: The Rise of Sprawl and the Decline of the American; Dream North Point: New York, NY, USA, 2000.

91. Salingaros, N.A. Complexity and urban coherence. J. Urban Des. 2000, 5, 291-316. [CrossRef]

92. Campbell, H. How Paris is Actually Walking the Climate Change Walk. Available online: https://time.com/5669067/parisgreen-city/ (accessed on 10 November 2020).

93. Folch-Serra, M. Place, voice, space: Mikhail Bakhtin's dialogical landscape. Environ. Plan. D Soc. Space 1990, 8, 255-274. [CrossRef]

94. Crang, M. Rhythms of the city: Temporalised space and motion. In Timespace: Geographies of Temporality; May, J., Thrift, N., Eds.; Routledge: London, UK, 2001; pp. 187-207.

95. DeLisle, J.R.; Grissom, T.V. An empirical study of the efficacy of mixed-use development: The Seattle experience. J. Real Estate Lit. 2013, 21, 25-57.

96. Sinxadi, L.; Awuzie, B.O.; Haupt, T. Tackling spatial inequalities through mixed income housing: A qualitative analysis of stakeholder perceptions. In Proceedings of the 14th International Postgraduate Conference, Manchester, UK, 3-14 August 2020.

97. Toker, Z.; Pontikis, K. An inclusive and generative design process for sustainable urbanism: The case of pacoima. J. Urban. Int. Res. Placemaking Urban Sustain. 2011, 4, 57-80. [CrossRef]

98. Whyte, W.H. City: Rediscovering the Center; Doubleday: New York, NY, USA, 1990.

99. Brookfield, K. Residents' preferences for walkable neighbourhoods. J. Urban Des. 2017, 22, 44-58. [CrossRef]

100. Nabil, N.A.; Eldayem, G.E.A. Influence of mixed land-use on realizing the social capital. HBRC J. 2015, 11, 285-298. [CrossRef]

101. Rodríguez-Pose, A.; von Berlepsch, V. Does population diversity matter for economic development in the very long term? Historic migration, diversity and county wealth in the US. Eur. J. Popul. 2019, 35, 873-911. [CrossRef]

102. Dembski, F.; Wössner, U.; Letzgus, M.; Ruddat, M.; Yamu, C. Urban digital twins for smart cities and citizens: The case study of Herrenberg, Germany. Sustainability 2020, 12, 2307. [CrossRef]

103. Kamel Boulos, M.N.; Tsouros, A.D.; Holopainen, A. 'Social, innovative and smart cities are happy and resilient': Insights from the who euro 2014 international healthy cities conference. Int. J. Health Geogr. 2015, 14, 3. [CrossRef]

104. Stamatiadis, N.; Pappalardo, G.; Cafiso, S. In Use of technology to improve bicycle mobility in smart cities. In Proceedings of the 5th IEEE International Conference on Models and Technologies for Intelligent Transportation Systems (MT-ITS), Napoli, Italy, 26-28 June 2017; pp. 86-91.

105. Cohen, N.; Rubinchik, A.; Shami, L. Towards a cashless economy: Economic and socio-political implications. Eur. J. Political Econ. 2020, 61, 101820. [CrossRef]

106. Han, C.; Wu, Y.; Chen, Z.; Wang, X. Terahertz communications (TeraCom): Challenges and impact on 6G wireless systems. arXiv 2019, arXiv:1912.06040.

107. Bolt, W.; Van Oordt, M.R.C. On the value of virtual currencies. J. Money Credit Bank. 2020, 52, 835-862. [CrossRef]

108. Neves, A.; Brand, C. Assessing the potential for carbon emissions savings from replacing short car trips with walking and cycling using a mixed GPS-travel diary approach. Transp. Res. Part A Policy Pract. 2019, 123, 130-146. [CrossRef]

109. Causone, F.; Sangalli, A.; Pagliano, L.; Carlucci, S. Assessing energy performance of smart cities. Build. Serv. Eng. Res. Technol. 2017, 39, 99-116. [CrossRef]

110. Chel, A.; Kaushik, G. Renewable energy technologies for sustainable development of energy efficient building. Alex. Eng. J. 2018, 57, 655-669. [CrossRef] 
111. Research and Market. Size is Expected to Grow from $\$ 410.8$ Billion in 2020 to $\$ 8201.7$ Billion. Available online: https: / / www.globenewswire.com/news-release/2020/10/05/2103315/0/en/Smart-Cities-Market-Report-2020-Global-Forecast-to2025-Market-Size-is-Expected-to-Grow-from-410-8-Billion-in-2020-to-820-7-Billion.html (accessed on 12 November 2020).

112. Pandey, N. Smart Cities Could Result in Social Inequality, Say Experts. Available online: https: / /www.thehindubusinessline. com/economy/smart-cities-could-result-in-social-inequality-say-experts/article9111629.ece (accessed on 11 November 2020).

113. Adkins, L.; Cooper, M.; Konings, M. Class in the 21st century: Asset inflation and the new logic of inequality. Environ. Plan. A Econ. Space 2019. [CrossRef]

114. Gurstein, P.; Hutton, T. Planning on the Edge: Vancouver and the Challenges of Reconciliation, Social Justice, and Sustainable Development; UBC Press: Vancouver, BC, Canada, 2019.

115. Van Vuren, T. The 30-minute city: Designing for access. Transp. Rev. 2020, 40, 685-686. [CrossRef]

116. Yang, L.; van Dam, K.H.; Majumdar, A.; Anvari, B.; Ochieng, W.Y.; Zhang, L. Integrated design of transport infrastructure and public spaces considering human behavior: A review of state-of-the-art methods and tools. Front. Archit. Res. 2019, 8, 429-453. [CrossRef] 